\title{
Influence of Fluid Intelligence on Accuracy of Metacognitive Monitoring in Preschool Children Fades with the Calibration Feedback
}

\author{
Kamila Urban \\ Institute for Research in Social Communication, \\ Slovak Academy of Sciences, \\ Bratislava, Slovak Republic
}

\author{
Marek Urban \\ Department of History and Theory of Art, \\ Faculty of Art and Design, \\ Jan Evangelista Purkyně University, \\ Ústí nad Labem, Czech Republic
}

\begin{abstract}
Higher fluid intelligence leads to better accuracy in metacognitive monitoring, but in school age this influence is moderated by the child's development and education. The goal of the study is to examine the interaction between fluid intelligence and performance feedback or calibration feedback on monitoring accuracy in 88 preschool children. The children in the group that received performance $(\mathrm{PF})$ or calibration feedback $(\mathrm{CF})$ were significantly more accurate at monitoring than the children without feedback (NF). Fluid intelligence correlated with monitoring accuracy for the whole dataset and explained $49 \%$ of variance in monitoring accuracy in the NF group; $26 \%$ in the PF group (feedback alone explained 20\%) and only $12 \%$ in the CF group, not reaching significance (however, feedback alone explained 26\%). Results indicate that calibration feedback could potentially fulfil the role of later education and development in improving monitoring accuracy and moderate the effect of fluid intelligence already in preschoolers.

Key words: fluid intelligence, monitoring accuracy, metacognition, feedback, preschool children
\end{abstract}

Metacognitive monitoring is the ability to monitor one's mental states and accurately assess how these states affect present and future performance in cognitive tasks (Nelson \& Narens, 1994). Monitoring ongoing activities is essential for planning and coordinating operations and resources that enable the person to choose, change or improve their strategy for

\section{Acknowledgment}

This research project was supported by the Scientific Grant Agency of the Ministry of Education of the Slovak Republic, grant VEGA 2/0134/18.

Correspondence concerning this article should be addressed to Mgr. Kamila Urban, PhD., Institute for Research in Social Communication SAS, Dubravska cesta 9,845 11 Bratislava, Slovak Republic. E-mail: kamila.p.urban@gmail.com

Received March 16, 2018 attaining educational goals. More accurate monitoring is required for better performance (Dunlosky \& Rawson, 2012; Roebers, Krebs, \& Roderer, 2014; Serra \& Metcalfe, 2009). Being overconfident about task performance often leads to worse study performance (Dunlosky \& Rawson, 2012), because the students do not spent sufficient time learning (Metcalfe \& Finn, 2008). For these reasons, Dunlosky and Rawson (2012) have suggested that an appropriate intervention could be developed to improve monitoring accuracy and decrease overconfidence.

We take up this suggestion and discuss the effect of performance feedback (Lipowski, Merriman, \& Dunlosky, 2013; Van Loon, Destan, Spiess, De Bruin, \& Roebers, 2017) and calibration feedback (Callender, Franco-Watkins, \& Roberts, 2016; Nietfeld, Cao, \& Osborne, 2006) on monitoring accuracy in preschool children 
solving analogical reasoning tasks. To evaluate the influence of performance feedback and calibration feedback on the accuracy of metacognitive monitoring in more detail, this study examines their interaction with fluid intelligence. Previous research has linked higher fluid intelligence with more accurate metacognitive monitoring (Rozencwajg, 2003; Saraç, Önder, \& Karakelle, 2014), and the present study will investigate whether proper feedback can moderate the influence of fluid intelligence on the accuracy of metacognitive monitoring.

\section{Development of Metacognitive Monitoring}

Being overconfident about one's performance is a life-long problem, and from preschool age individuals increasingly learn to judge their performance with greater accuracy on a continuum from very sure to very unsure (Flavell, 2000). For many years it was assumed that metacognitive skills develop from primary school age and that preschool children are not able to monitor their performance more accurately and are often overconfident (for review: Lipko, Dunlosky, \& Merriman, 2009; Schneider, 1998). But a number of researchers have found that children are able to monitor their own uncertainty from the age of 3 (Lyons \& Ghetti, 2011; Marulis, Palincsar, Berhenke, \& Whitebread, 2016), seeking help when they are unsure about perception tasks (Coughlin, Hembacher, Lyons, \& Ghetti, 2015) or skipping an item when they are not sure whether they know the solution (Balcomb \& Gerken, 2008). From the age of 5 children learn to differentiate correct solutions from incorrect solutions when completing more complex memory tasks (Destan \& Roebers, 2015; Hembacher \& Ghetti, 2014) and analogical reasoning tasks (Urban, Van Loon, \& Roebers, 2016).

The development of the ability to monitor one's performance also depends on the nature of the task and socioeconomic background
(Lipko et al., 2009; Urban, 2017; Zápotočná, 2013). Urban and Zápotočná (2017) used two Piagetian tasks and two text-comprehension tasks to test the ability of preschool children ( 5 and 6 year olds) to monitor performance. They found that children were more accurate in monitoring text comprehension tasks than Piagetian tasks. Urban (2017) found that while 5 and 6 year old children from middle class families correctly monitored their correct answers on text comprehension tasks in $90-96 \%$ of cases, children from lower socioeconomic backgrounds monitored their correct responses significantly less accurately.

Researchers are therefore interested in finding ways to decrease overconfidence in preschool children (Lipko et al., 2009; Urban et al., 2016; Van Loon et al., 2017) and in gaining a better understanding of the influence social and individual factors have on metacognition (Arslan, Akin, \& Çítemel, 2013; Sarikam, 2015; Urban, 2017; Urban \& Zápotočná, 2017; Zápotočná, 2013). As we will discuss further, one of these factors is intelligence (Alexander, Johnson, Albano, Freygang, \& Scott, 2006; Veenman \& Spaans, 2005).

\section{Intelligence and Metacognition}

Three general theories about the relationship between metacognition and intelligence have developed over time. The first model regards metacognition as the manifestation of intellectual ability and as an integral part of the cognitive toolbox. According to this intelligence model, metacognitive skills cannot have a predictive value for learning independent of intellectual ability (Sternberg, 1979). In the second, contrasting model, intellectual ability and metacognition are regarded as entirely independent predictors of learning, that is, as entirely separate toolboxes (Swanson, 1990). Finally, according to the mixed model, metacognition is related to intellectual ability to a certain extent, 
but it also has a surplus value on top of the intellectual ability for the prediction of learning (Van der Stel \& Veenman, 2014; Veenman, Kok, \& Blöte, 2005; Veenman, Wilhelm, \& Beishuizen, 2004). The independence and mixed models imply that metacognition can be fostered regardless of intelligence, suggesting the efficacy of metacognitive training for children with a whole range of intellectual abilities.

A closer examination of previous research reveals that the relationship between metacognition and intelligence depends on the components of metacognition (knowledge, monitoring and control) and the nature of intelligence (fluid or crystallized) investigated in the research (Alexander, Carr, \& Schwanenflugel, 1995). In general, children of higher intelligence demonstrate better metacognitive knowledge (Alexander et al., 2006; Alexander \& Schwanenflugel, 1996; Swanson, 1992) and metacognitive monitoring (Slife, Weiss, \& Bell, 1985; Snyder, Nietfeld, \& Linnenbrink-Gracia, 2011). Highly intelligent students (aged 12 and 15) exhibited more metacognitive activities relative to students with lower intelligence (Veenman \& Spaans, 2005). In research with 12 and 13 year olds, Rozencwajg (2003) found a high correlation between crystallized intelligence and metacognitive knowledge, while metacognitive monitoring was more closely associated with fluid intelligence. In the same age group, Saraç et al. (2014) discovered a significant correlation between fluid intelligence and metacognitive monitoring, but did not find a significant correlation between fluid intelligence, metacognitive knowledge and metacognitive control.

In the learning environment, metacognitive abilities in general outweigh intelligence as a predictor of learning performance (Minnaert \& Janssen, 1999; Pishghadam \& Khajavy, 2013; Van der Stel \& Veenmam, 2014; Veenman et al., 2005). More importantly, research suggests that intelligence has a decreasing influence during child development and education (Veenman et al., 2004), but that the impact of metacognition on learning performance remains important throughout the whole lifespan (Dunlosky \& Rawson, 2012; Metcalfe \& Finn, 2008; Roebers, 2017).

These conclusions indicate the need to foster metacognition rather than intelligence to achieve better learning performance (Sarzyńska, Żelechowska, Falkiewicz, \& Nęcka, 2017). Pet'ková (2014) created a metacognitive (thinkaloud) intervention for preschool children scoring below the 10th percentile in performance on Piagetian tasks. The children performed significantly better in post-test. The next section therefore examines the role of intervention in fostering metacognition.

\section{Interventions Fostering Metacognition}

There are basically two interventional strategies for improving metacognition. Firstly, there are repeated measures research designs, in which the same kind of task is repeatedly solved with the assumption that more experience solving similar tasks improves both performance and accuracy (Kruger \& Dunning, 1999). However, while adults become underconfident after the first study trial (Finn \& Metcalfe, 2014), children do not become underconfident with practice (Lipko et al., 2009), therefore, for children the use of repeated measures design is insufficient on its own.

Secondly, different kinds of feedback are given externally after task-solving. In research by Van Loon et al. (2017) two age groups (6 and 8 year olds) were overconfident about incorrect responses, but benefited from performance feedback (information on whether the task solution was correct or incorrect). However, the bulk of the research suggests that children's predictions about future performance are minimally influenced by their past performance or performance feedback (Lipko et al., 2009; 
Lipowski et al., 2013). Following this assumption, Hembacher and Ghetti (2014) asked whether preschoolers might benefit from an intervention that emphasized the monitoring accuracy.

Feedback on calibration is commonly used to target the accuracy of metacognitive monitoring. Calibration is the relationship between performance and monitoring judgment on an item-by-item basis (Dunlosky \& Thiede, 2013; Hacker, Bol, \& Bahbahani, 2008; Nietfeld et al., 2006; Schraw, 2009). Therefore, calibration feedback provides information about the correctness of task performance as well as the accuracy of the metacognitive judgment regarding it. Most promising are mixed interventional designs that benefit from both repeated testing and provided feedback (Hacker, Bol, \& Keener, 2008), especially in low performing students (Krajč, 2008; Miller \& Geraci, 2011; Ryvkin, Krajč, \& Ortmann, 2012). Nietfeld et al. (2006) found a significant treatment effect (repeated testing) on monitoring accuracy and performance in students who received monitoring feedback (overall calibration and bias scores) but not in students who received no feedback. In a similar setting Callender et al. (2016) found significant improvements in performance and metacognitive accuracy in students.

\section{Present Study}

In the present study we tested the effect of two interventions designed to enhance accuracy of metacognitive monitoring in preschool children: performance feedback (Van Loon et al., 2017) and calibration feedback (Nietfeld et al., 2006). We assume that the children in the group without feedback (hereafter NF) will be significantly more overconfident than children in the groups who receive performance feedback (hereafter PF) and calibration feedback (hereafter CF). This is hypothesis 1(a). Previ- ous research indicates that performance feedback has a smaller effect on metacognitive accuracy in this age group (Lipko et al., 2009; Van Loon et al., 2017), so we assume that the children in the CF group will be the least overconfident. This is hypothesis 1(b).

To further examine the influence of performance feedback and calibration feedback on the accuracy of metacognitive monitoring, we will investigate the explanatory effect of fluid intelligence on accuracy of metacognitive monitoring in all three groups (NF, PF, CF). Following research by Rozencwajg (2003) and Saraç et al. (2014), we assume that fluid intelligence positively correlates with the accuracy of metacognitive monitoring, that is, children with a higher fluid intelligence will be more accurate in their monitoring. This is hypothesis 2(a). But research by Veenman et al. (2004) suggests that metacognition is only partly dependent on intelligence and that with continuing development and education, the influence of intelligence fades. We are interested whether also feedback can moderate the relationship between intelligence and monitoring accuracy. For this reason we assume that intelligence will explain less variance in the PF and CF groups, because of the effect of performance feedback and calibration feedback. This is hypothesis 2(b).

\section{Method}

\section{Participants}

The sample described in Table 1 consisted of a total of 88 children ( 33 girls and 55 boys) from 5.0 to 6.7 years old (mean age $=6.2$ years, $S D=$ $0.4)$. All the children were purposely recruited and tested in eight public preschools in Slovakia and were native Slovak speakers. The participants were predominantly Caucasian and from middle class families. Written consent was obtained from the children's parents and verbal assent from the children. 
Table 1 Number of participants, mean age and mean score in Coloured Progressive Matrices (CPM) among the feedback groups. (Standard deviations of the mean in parentheses.)

\begin{tabular}{lcccc} 
& NF & $P F$ & $C F$ & Overall \\
\hline N of Participants & $28(9$ girls $)$ & $29(10$ girls $)$ & $31(14$ girls $)$ & $88(33$ girls $)$ \\
Mean Age & $6.19(.40)$ & $6.30(.31)$ & $6.06(.44)$ & $6.18(.40)$ \\
Mean CPM score & $24.39(3.96)$ & $25.21(3.66)$ & $24.16(3.35)$ & $24.58(3.64)$ \\
\hline
\end{tabular}

Note. Separate ANOVAs did not show significant effect of feedback group on age, fluid intelligence and gender $[F(2,85)=2.61, p=\mathrm{ns}$.; $F(2,85)=.67, p=\mathrm{ns}$.; $F(2,85)=.60, p=$ ns., respectively]

\section{Measures}

The Analogical Reasoning Tasks were adapted from the mini LÜK children's game (two examples of tasks are present in the Appendix). We used 10 tasks (e.g., Urban et al., 2016) in which children had to analogically relate targets according to color (1 task), shape (3 tasks), color and shape (3 tasks) and complete a pattern ( 3 tasks). Each of the 10 tasks consisted of 12 target items, which were solved in the same way as the example. There was one correct solution for each target item on the solution sheet. The solution sheet was the same for all 12 target items and each child had 12 possible solutions to choose from for each item.

The metacognitive monitoring judgments were provided retrospectively (confidence judgments) by each child for each item solved. The children used a two-color traffic light system: red and green (e.g., Urban, 2017; Urban et al., 2016; Urban \& Zápotočná, 2017). The children selected green if they thought the response to the task was correct and red if they thought the response to the task was incorrect.

Fluid intelligence was measured by Coloured Progressive Matrices, CPM (Raven, Court, \& Raven, 1991). The CPM contains three sections with 12 tasks of increasing difficulty. Each task consisted of an incomplete design and the chil- dren were given six alternatives to select a solution. Each section increased in difficulty and knowledge from the previous item was required to answer the next item.

\section{Procedure}

The data were collected on five consecutive days. The children were randomly assigned to one of the three groups (NF, PF and CF) before the first testing. They were tested individually by the first author before noon in a quiet room in the preschool. Before the first testing, the Coloured Progressive Matrices (CPM) were administered individually by a trained experimenter.

The order of the testing was altered each day and the testing lasted from 10 to 15 minutes per child. The task order and assessment procedure were identical for all children. Each day, the children solved two analogical reasoning tasks and provided monitoring judgments on their performance. The children analogically solved the 12 items in each task using the example by pointing to the answer on the solution sheet. After each item was solved, the experimenter elicited a monitoring judgment by asking: "Do you think you got it right or wrong? Show me using the traffic light." The traffic light system had been explained before testing through the telling of a short story about how 
we cross the street and when we can be sure we can cross and how the children should point to the red and green colors of the traffic light to indicate whether they thought their response was correct or incorrect. The experimenter explained: "Point to the green if you think your answer was right, and point to the red if you think your answer was wrong." The explanation was concluded once it had been ascertained the child understood.

\section{Feedback}

The difference in the experimental conditions lies in the feedback provided. The children in the control group (NF) solved each task and provided metacognitive monitoring judgments once they had solved each item.

The children in the PF group solved each item, provided a monitoring judgment and finally received performance feedback from the experimenter as to whether their response was correct. When the response was correct, the experimenter said: "Yes, it was the right answer". When the answer was incorrect the experimenter said: "No, it was not the right answer."

The children in the CF group solved each item, provided a monitoring judgment and finally received calibration feedback on the accuracy of their judgment and the correctness of their answer. After the children provided a monitoring judgment for a solved item, the experimenter provided one of four types of feedback: a) When the solution was correct and the child pointed at the green light the experimenter said: "Well done, you thought your answer was correct and indeed it was." b) When the solution was incorrect and the child pointed at the green light the experimenter said: "Oh no, you thought your answer was correct but it was not." c) When the solution was incorrect and the child pointed at the red light, the experimenter said: "Well done, you thought you gave the wrong an- swer and indeed, you did." d) When the answer was correct and the child pointed to the red light, the experimenter said: "Oh no, you thought you gave the wrong answer, but it was actually right," (e.g., Urban et al., 2016).

\section{Data Analysis}

To assess monitoring accuracy, we first calculated the mean Bias Index from the 10 tasks (120 items) for each child. The Bias Index shows the discrepancy between confidence judgment (a "red" light was coded 0 and a "green" light 1 ) and performance ( 0 for an incorrect answer, and 1 for a correct answer). Moreover, the Bias Index assesses the degree to which the children are overconfident or underconfident by providing information about the direction of the discrepancy between the specific judgment and the performance. If the confidence judgment is high and the performance low, the individual is overconfident, and the value of the Bias Index is close to 1 . If the confidence judgment is low and the performance is high, underconfidence occurs, and the value of the Index is close to -1 . The closer to 0 the value is, the more it reflects better accuracy (Schraw, 2009).

To test our hypothesis concerning the influence feedback has on the accuracy of monitoring judgments, a one-way ANOVA was conducted in SPSS 20. The independent variable was the feedback groups (NF, PF, CF), and the dependent variable was the Bias Index. A significant main effect was followed up with a Posthoc Tukey test. Next, correlation analyses were performed to determine the strength of the relationship between fluid intelligence and accuracy of metacognitive monitoring in the three groups separately. Finally, a hierarchical regression analysis was conducted to predict the influence of feedback (PF or CF) and fluid intelligence on the accuracy of metacognitive monitoring. 


\section{Results}

In the results section we first test our hypothesis that performance feedback and calibration feedback have a positive impact on the accuracy of preschool children's metacognitive monitoring. We then report on whether the children in the CF group are the most accurate or not. Then we investigate the relationship between children's intelligence and accuracy of metacognitive monitoring. In the analysis that follows we examine the explanatory effect of intelligence on the accuracy of metacognitive monitoring in the NF control group and the PF and $\mathrm{CF}$ experimental groups. Finally, we ascertain whether performance and calibration feedback explain more variance in the accuracy of metacognitive monitoring than intelligence does.
In hypothesis 1(a), we assumed there is a significant difference in the accuracy of metacognitive monitoring between all three groups (NF, $\mathrm{CF}, \mathrm{PF})$. Hypothesis 1(b) states that the $\mathrm{CF}$ group will be the least overconfident. The analysis of variance (ANOVA) yielded significant variation among the feedback groups $[F(2,85)$ $\left.=14.84, p<.001, \eta p^{2}=.26\right]$ and supports hypothesis 1(a). Figure 1 shows children's monitoring accuracy for each group. The post hoc Tukey test indicates that the PF group ( $M=$ $0.13, S D=0.06)$ was significantly less overconfident $(p<.001)$ than the NF group $(M=0.24$, $S D=0.15)$, and also the CF group $(M=0.11$, $S D=0.07)$ was significantly less overconfident $(p<.001)$ than the NF group. However, the difference between the PF and CF groups was not significant (0.02, 95\% CI: [-0.04-0.08], $p=.74)$. Hypothesis 1(b) is therefore only partially supported. These results indicate the positive im-

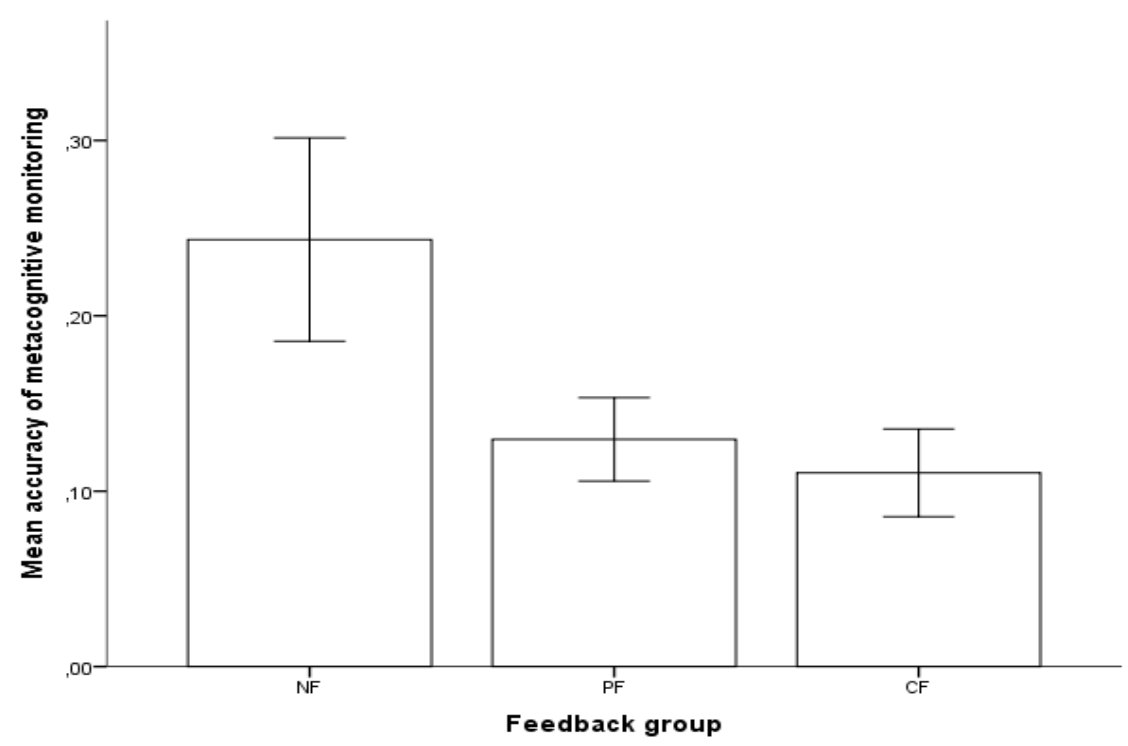

Note. Closer to zero indicates more accurate monitoring

Figure 1 Mean monitoring accuracy in feedback groups (NF, PF, CF). Error bars indicate a 95\% confidence interval 
pact performance feedback and calibration feedback have on preschoolers' metacognitive accuracy, but at this point we cannot assume that it is the calibration feedback that makes the children less overconfident rather than the performance feedback. To better understand the performance and calibration feedback effects we will describe their interaction with intelligence.

Hypothesis 2(a) assumed that fluid intelligence positively correlates with accuracy of metacognitive monitoring, that is, children of higher intelligence are less overconfident in monitoring. But hypothesis 2(b) suggests that intelligence explains less variance in the PF and $\mathrm{CF}$ groups because of the effect of performance feedback and calibration feedback respectively. As we can see in Table 2, the Pearson's $r$ data analysis revealed a significant correlation between intelligence and monitoring accuracy in the NF group $(r=-.699, n=28, p<.001)$ and less significant correlation in the PF group ( $r=$ $-.513, n=29, p=.005)$. Surprisingly, there was no correlation between intelligence and accuracy of metacognitive monitoring in the $\mathrm{CF}$ group $(r=-.339, n=31, p=.061)$. However, the
Pearson's $r$ data analysis for the whole dataset revealed a significant correlation between intelligence and monitoring accuracy $(r=-.471$, $n=88, p<.001)$. Also, Fisher's $r$-to- $z$ transformation did not proved significant differences between correlations in the NF and PF group $(z=-1.07, p=.285)$ and the NF and CF group $(z=-1.87, p=.062)$. Therefore, we conclude hypothesis 2(a) as supported.

To better understand the interaction of intelligence and feedback on the accuracy of metacognitive monitoring, we conducted a hierarchical regression analysis with intelligence entered in the equation first for all three groups (NF, PF, CF) separately. As we can see in Table 3 , intelligence alone explains $49 \%$ of the variance in accuracy of metacognitive monitoring in the NF group, $26 \%$ in the PF group and only $12 \%$ in $\mathrm{CF}$ group not reaching significance $[F(1,29)=3.79, p=.061]$. These results indicate the weakening influence of intelligence in the $\mathrm{PF}$ and $\mathrm{CF}$ groups.

To examine the effect of feedback alone, performance feedback (for the PF group) and calibration feedback (for the CF group) were en-

Table 2 Correlation between fluid intelligence and monitoring accuracy in feedback groups

\begin{tabular}{lcccc}
\hline & $N F$ & $P F$ & $C F$ & Overall \\
\hline Correlation Intelligence / Accuracy & $-.699^{* * *}$ & $-.513^{* *}$ & -.339 & $-.471^{* * *}$ \\
\hline Note. ${ }^{* *} p<.01 ; * * * p .001$ & & & &
\end{tabular}

Table 3 Percentage of variance accounting for metacognitive accuracy

\begin{tabular}{lccc}
\hline & Intelligence unique & Feedback unique & Shared \\
\hline NF & 49 & - & - \\
PF & 26 & 20 & 56 \\
CF & 12 & 26 & 57 \\
\hline
\end{tabular}

Note. Intelligence unique refers to the unique contribution of fluid intelligence to the accuracy of metacognitive monitoring; Feedback unique refers to the unique contribution of feedback (performance feedback in the PF group, and calibration feedback in the CF group) to the accuracy of metacognitive monitoring; Shared refers to the shared contribution of fluid intelligence and feedback to the accuracy of metacognitive monitoring. 
tered into the equation alone (dummy coded). Performance feedback alone explained $20 \%$ of the variance, and calibration feedback alone explained $26 \%$. The calibration feedback had a greater explanatory effect than performance feedback. Together these findings support hypothesis 2(b).

In the second step, in the PF group, intelligence and performance feedback together explained $50 \%$ of the variation in accuracy of metacognitive monitoring reaching significance at level $p<.001$. Next, the interaction term between intelligence and performance feedback was added to the regression model, which accounted for a significant proportion of the variation in monitoring accuracy $(p<.001)$. This model explained $56 \%$ of the variation in monitoring accuracy, with significant influence of both intelligence $(\beta=-.03, p<.001)$ as well as performance feedback $(\beta=-.53, p=.001)$.

In the $\mathrm{CF}$ group intelligence and calibration feedback together explained $50 \%$ of the variance in accuracy of metacognitive monitoring reaching significance at level $p<.001$. Together with the interaction term between intelligence and calibration feedback the regression model explained $57 \%$ of the variation in monitoring accuracy again with significant influence of both intelligence $(\beta=-.03, p<.001)$ as well as calibration feedback $(\beta=-.61, p<.001)$.

Comparing the standardized beta coefficients we can see that calibration feedback had a stronger influence than did performance feedback on the accuracy of metacognitive monitoring. The findings from the regression analysis further support hypothesis 1(b).

\section{Discussion}

In the present study we investigated the influence of performance feedback and calibration feedback on monitoring accuracy in preschool children and how the two kinds of feedback interacted with fluid intelligence. The chil- dren solved 10 analogical reasoning tasks in five consecutive days and provided confidence judgments once each item had been solved.

We found a strong relationship between fluid intelligence and accuracy of metacognitive monitoring in preschool children. The children in the group with no additional feedback and with higher fluid intelligence were less overconfident than the children with lower intelligence. Our results with the preschool children correspond to the findings of previous studies conducted with primary school children (Rozencwajg, 2003; Saraç, Önder, \& Karakelle, 2014). In our research, fluid intelligence explained $49 \%$ of the variance in monitoring accuracy in preschool children solving analogical reasoning tasks.

However, our findings from the feedback groups indicate that the influence of fluid intelligence on the accuracy of metacognitive monitoring can be moderated by feedback. This supports the previous line of research, which found that education and development leads to metacognition becoming partly independent from intelligence (Van der Stel \& Veenman, 2014; Veenman et al., 2005) and to the children gaining better metacognitive accuracy (Finn \& Metcalfe, 2014; Flavell, 2000; Roebers et al., 2014; Van Loon et al., 2017). We found that both (performance and calibration) feedback ameliorated children's monitoring accuracy. The preschool children in the two feedback groups were significantly less overconfident than their peers in the control group. At this point we should add that research with wider sample of children would also better examine the effect of performance and calibration feedback, while our research did not prove the significant differences in metacognitive accuracy between the PF and CF group.

However, performance feedback alone explained $20 \%$ of the variance in monitoring accuracy, indicating that performance feedback has a significant influence on monitoring accu- 
racy. In the performance feedback group, fluid intelligence explained $26 \%$ of the variance in monitoring accuracy, indicating that fluid intelligence had a smaller influence when compared to the non-feedback group $(26 \%<49 \%)$. The results of the performance feedback group correspond to previous research, where it was assumed that preschool age children remained overconfident because they could not take full account of the performance feedback when monitoring their performance (Lipko et al., 2009; Lipowski et al., 2013; Van Loon et al., 2017). In our study, the preschool children in the performance feedback group monitored their performance more accurately than did the children without the feedback, but fluid intelligence still had a significant influence on their monitoring accuracy. The children with a lower fluid intelligence continued to display greater overconfidence even after the performance feedback had been administered.

Calibration feedback, in the line with previous research (Krajč, 2008; Miller \& Geraci, 2011; Ryvkin et al., 2012), seems to produce more promising results. Calibration feedback alone explained $26 \%$ of the variance in monitoring accuracy; $6 \%$ more than performance feedback did. But more importantly, in the calibration feedback group, fluid intelligence explained only $12 \%$ of the variance in monitoring accuracy, and it was not significant. These results indicate the potential of calibration feedback to fulfill the role of later education and development in fostering metacognition already at the preschool age. In other words, preschool children can learn to better monitor their performance despite their level of fluid intelligence thanks to the calibration feedback.

These findings further support the mixed model of metacognition and intelligence (Van der Stel \& Veenman, 2014; Veenman et al., 2004; 2005). We can see the influence of fluid intelligence on the accuracy of metacognitive monitoring under conditions where there is no inter- vention, but the effect of intelligence fades due to the feedback.

However, future research should address the question of whether preschool children can retain the performance feedback or calibration feedback effect for longer periods as well (Sarzyńska et al., 2017). While our sample consisted of 5 to 6 year olds, it would be beneficial to investigate the potential additional effect performance feedback or calibration feedback may have on top of the ordinary educational and developmental effects of the first year of primary school. Moreover, Ryvkin et al. (2012) described the changing effect of performance and calibration feedback while solving different kinds of tasks in different environments, therefore it would be beneficial to research more closely the differences between performance and calibration feedback in experimental and real learning environments.

Nevertheless, these findings could have an impact on everyday classroom practice. Calibration feedback can be beneficial for children with lower fluid intelligence, as the present study has shown, but it is also of benefit to children with learning disabilities who constantly overestimate their performance (Slife et al., 1985) and for children from lower socioeconomic backgrounds, who cannot monitor their performance accurately (Urban, 2017).

\section{References}

Alexander, J. M., Carr, M., \& Schwanenflugel, P. J. (1995). Development of metacognition in gifted children: Directions for future research. Developmental Review, 15, 1-37.

Alexander, J. M., Johnson, K. E., Albano, J., Freygang, T., \& Scott, B. (2006). Relations between intelligence and the development of metaconceptual knowledge. Metacognition and Learning, 1, 51-67.

Alexander, J. M., \& Schwanenflugel, P. J. (1996). Development of metacognitive concepts about thinking in gifted and nongifted children: Recent research. Learning and Individual Differences, 8(4), 305-325.

Arslan, S., Akin, A., \& Çítemel, N. (2013). The predictive role of grit on metacognition in Turkish uni- 
versity students. Studia Psychologica, 55(4), 311320 .

Balcomb, F. K., \& Gerken, L. (2008). Three-year-old children can access their own memory to guide responses on a visual matching task. Developmental Science, 11(5), 750-760.

Callender, A. A., Franco-Watkins, A. M., \& Roberts, A. S. (2016). Improving metacognition in the classroom through instruction, training, and feedback Metacognition and Learning, 11(2), 215-235.

Coughlin, C., Hembacher, E., Lyons, K. E., \& Ghetti, S. (2015). Introspection on uncertainty and judicious help-seeking during the preschool years. $D e$ velopmental Science, 18(6), 957-971.

Destan, N., \& Roebers, C. M. (2015). What are the metacognitive costs of young children's overconfidence? Metacognition and Learning, 10(3), 347374.

Dunlosky, J., \& Rawson, K. A. (2012). Overconfidence produces underachievement: Inaccurate self-evaluations undermine students' learning and retention. Learning and Instruction, 22, 271-280.

Dunlosky, J., \& Thiede, K. W. (2013). Four cornerstones of calibration research: Why understanding students' judgments can improve their achievement. Learning and Instruction, 24(1), 58-61.

Finn, B., \& Metcalfe, J. (2014). Overconfidence in children's multi-trial judgments of learning. Learning and Instruction, 32, 1-9.

Flavell, J. H. (2000). Development of children's knowledge about the mental world. International Journal of Behavioral Development, 24(1), 15-23.

Hacker, D. J., Bol, L., \& Bahbahani, K. (2008). Explaining calibration accuracy in classroom context: The effects of incentives, reflection, and explanatory style. Metacognition and Learning, 3(2), 101-121.

Hacker, D. J., Bol., L., \& Keener, M. C. (2008). Metacognition in education: A focus on calibration. In J. Dunlosky, \& R. A. Bjork (Eds.), Handbook of memory and metacognition (pp. 429-455). New York, NY, US: Psychology Press.

Hembacher, E., \& Ghetti, S. (2014). Don't look at my answer: Subjective uncertainty underlies preschoolers' exclusion of their least accurate memories. Psychological Science, 25(9), 1768-1776.

Krajč, M. (2008). Are the unskilled really that unaware? Understanding seemingly biased self-assessments. Prague: CERGE-EI.

Kruger, J., \& Dunning, D. (1999). Unskilled and unaware of it: How difficulties in recognizing one's own incompetence lead to inflated self-assessments. Journal of Personality and Social Psychology, 77(6), 1121-1134.

Lipko, A. R., Dunlosky, J., \& Merriman, W. E. (2009). Persistent overconfidence despite practice: The role of task experience in preschoolers' recall predictions. Journal of Experimental Child Psychology, $103,152-166$.

Lipowski, S. L., Merriman, W. E., \& Dunlosky, J. (2013). Preschoolers can make highly accurate judgments of learning. Developmental Psychology, 49(8), 1505-1516.

Lyons, K. E., \& Ghetti, S. (2011). The development of uncertainty monitoring in early childhood. Child Development, 82(6), 1778-1787.

Marulis, L. M., Palincsar, A. S., Berhenke A. L., \& Whitebread, D. (2016). Assessing metacognitive knowledge in 3-5 year olds: The development of a metacognitive knowledge interview (McKI). Metacognition and Learning, 11(3), 339-368.

Metcalfe, J., \& Finn, B. (2008). Evidence that judgments of learning are causally related to study choice. Psychonomic Bulletin and Review, 15(1), 174-179.

Miller, T. M., \& Geraci, L. (2011). Training metacognition in the classroom: The influence of incentives and feedback on exam predictions. Metacognition and Learning, 6(3), 303-314.

Minnaert, A., \& Janssen, P. J. (1999). The additive effect of regulatory activities on top of intelligence in relation to academic performance in higher education. Learning and Instruction, 9, 77-91.

Nelson, T. O., \& Narens, L. (1994). Why investigate metacognition? In J. Metcalfe, \& A. P. Shimamura (Eds.), Metacognition: Knowing about knowing (pp. 1-25). Cambridge, MA: MIT Press.

Nietfeld, J. L., Cao, L., \& Osborne, J. W. (2006). The effect of distributed monitoring exercises and feedback on performance, monitoring accuracy, and selfefficacy. Metacognition and Learning, 1(2), 159179.

Pet'ková, K. (2014). The use of zone of proximal development when solving Piagetian tasks in preschool children. Proceedings of the International Scientific Conference on MMK 2014 (vol. V., pp. 2122-2131). Hradec Králové: Magnanimitas.

Pishghadam, R., \& Khajavy, G. H. (2013). Intelligence and metacognition as predictors of foreign language achievement: A structural equation modeling approach. Learning and Individual Differences, 24 , 176-181.

Raven, J. C., Court, J. H., \& Raven, J. (1991). Farebné progresivne matice (CPM). Bratislava: Psychodiagnostika.

Roebers, C. M. (2017). Executive function and metacognition: Towards a unifying framework of cognitive self-regulation. Developmental Review, 45, 31-51.

Roebers, C. M., Krebs, S. S., \& Roderer, T. (2014). Metacognitive monitoring and control in elementary school children: The interrelations and their 
role for test performance. Learning and Individual Differences, 29, 141-149.

Rozencwajg, P. (2003). Metacognitive factors in scientific problem-solving strategies. European Journal of Psychology of Education, 18(3), 281-294.

Ryvkin, D., Krajč, M., \& Ortmann, A. (2012). Are the unskilled doomed to remain unaware? Journal of Economic Psychology, 33(5), 1012-1031.

Saraç, S., Önder, A., \& Karakelle, S. (2014). The relations among general intelligence, metacognition and text learning performance. Education and Science, 39(173), 40-53.

Sariçam, H. (2015). Metacognition and happiness: The mediating role of perceived stress. Studia Psychologica, 57(4), 271-283.

Sarzyńska, J., Żelechowska, D., Falkiewicz, M., \& Nęcka, E. (2017). Attention training in school children improves attention but fails to enhance fluid intelligence. Studia Psychologica, 59(1), 50-65.

Schneider, W. (1998). Performance prediction in young children: Effects of skill, metacognition and wishful thinking. Developmental Science, 1(2), 291-297.

Schraw, G. (2009). Measuring metacognitive judgments In D. J. Hacker, J. Dunlosky, \& A. C. Graesser (Eds.) Handbook of metacognition in education (pp. 415429). New York, NY: Routledge.

Serra, M. J., \& Metcalfe, J. (2009). Effective implementation of metacognition. In D. J. Hacker, J. Dunlosky, \& A. C. Graesser (Eds.), Handbook of metacognition in education (pp. 278-298). New York, NY: Routledge.

Slife, B. D., Weiss, J., \& Bell, T. (1985). Separability of metacognition and cognition: Problem solving in learning disabled and regular students. Journal of Educational Psychology, 77(4), 437-445.

Snyder, K. E., Nietfeld, J. L., \& Linnenbrink-Garcia, L. (2011). Giftedness and metacognition: A shortterm longitudinal investigation of metacognitive monitoring in the classroom. Gifted Child Quarterly, 55(3), 181-193.

Sternberg, R. J. (1979). The nature of mental abilities. American Psychologist, 34(3), 214-230.

Swanson, H. L. (1990). Influence of metacognitive knowledge and aptitude on problem solving. Journal of Educational Psychology, 82(2), 306-314.

Swanson, H. L. (1992). The relationship between metacognition and problem solving in gifted children. Roeper Review, 15(1), 43-48.
Urban, K. (2017). Metakognitívny monitoring [Metacognitive monitoring]. In O. Zápotočná, \& Z. Petrová (Eds.), Raná jazyková gramotnost' detí zo socioekonomicky znevýhodneného prostredia [Early literacy of children from socioeconomically disadvantage backgrounds] (pp. 7998). Trnava: Typi Universitatis Tyrnaviensis \& Bratislava: VEDA.

Urban, K., Van Loon, M. H. \& Roebers, C. (2016, August 23 to 26). Metacognitive monitoring in preschool children when solving analogical reasoning tasks. In Metacognition 2016: Proceedings of the 7th Biennial Meeting of the EARLI Special Interest Group 16 Metacognition. Nijmegen, Radboud University Nijmegen, 2016, 118

Urban, K., \& Zápotočná, O. (2017). Metakognitívny monitoring pri riešení verbálnych a neverbálnych úloh u detí predškolského veku [Metacognitive monitoring in preschool children when solving verbal and nonverbal tasks]. Československá Psychologie, 61(6), 521-535.

Van Loon, M. H., Destan, N., Spiess, M., De Bruin, A. B. H., \& Roebers, C. (2017). Developmental progression in performance evaluations: Effects of children's cue-utilization and self-protection. Learning and Instruction, 51, 47-60.

Van der Stel, M., \& Veenman, M. V. J. (2014). Metacognitive skills and intellectual ability of young adolescents: A longitudinal study from a developmental perspective. European Journal of Psychology of Education, 29(1), 117-137.

Veenman, M. V. J., Kok, R., \& Blöte, A. W. (2005). The relation between intellectual and metacognitive skills in early adolescence. Instructional Science, 33, 193-211.

Veenman, M. V. J., \& Spaans, M. A. (2005). Relation between intellectual and metacognitive skills: Age and task differences. Learning and Individual Differences, 15, 159-176.

Veenman, M. V. J., Wilhelm, P., \& Beishuizen, J. J. (2004). The relation between intellectual and metacognitive skills from a developmental perspective. Learning and Instruction, 14, 89-109.

Zápotočná, O. (2013). Metakognitívne procesy v čítaní, učení a vzdelávaní [Metacognitive processes in reading, learning and education]. Trnava: Typi Universitatis Tyrnaviensis. 
Appendix

Examples of analogical reasoning tasks.

a) Task used in Session 1.

Combine the pieces correctly!
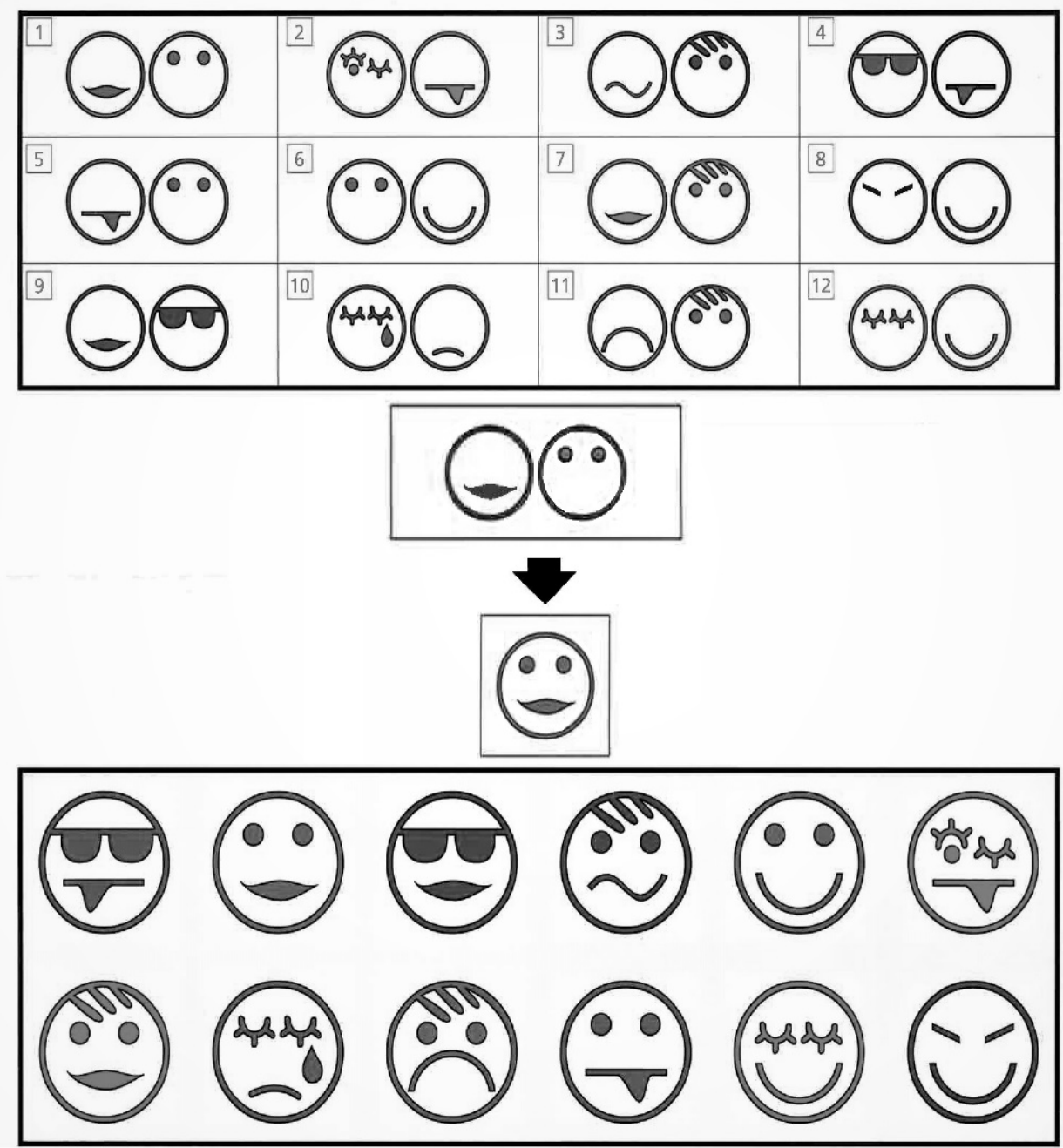
b) Task used in Session 5 .

\section{What is the next step?}

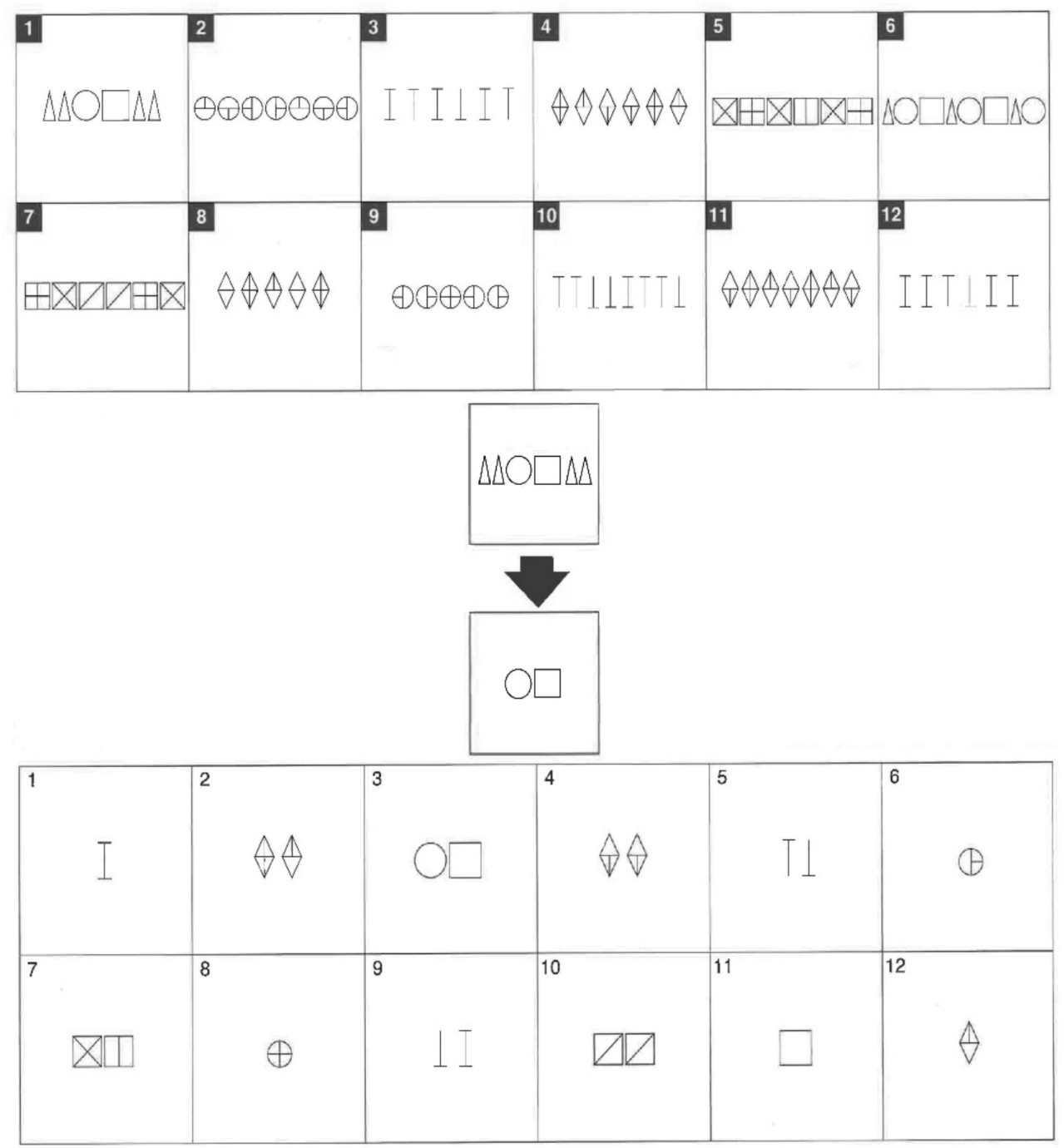

